\title{
La etnografía: instrumento de investigación en antropología jurídica. El caso de un pueblo amazónico ${ }^{1}$
}

\author{
Roberto Narváez Collaguazo ${ }^{2}$
}

Fecha de recepción: 30 de julio de 2018

Fecha de aprobación: 17 de octubre de 2018

\begin{abstract}
Resumen
La antropología jurídica remite su ámbito de investigación e interpretación a los sistemas jurídicos que establecen el orden interno de las sociedades, y tiene en la etnografía un método de investigación que permite un acercamiento sistemático a las prácticas y particularidades culturales de los grupos sociales, analizándolos y desarrollando una descripción que nos permite una comprensión de sus aspectos culturales. La antropología jurídica utiliza la etnografía como un método para comprender el orden social y los sistemas legales imperantes en un grupo humano. El estudio de caso nos remite al pueblo waorani que habita la Amazonía ecuatoriana, contactado en la década del sesenta del siglo anterior y en proceso de cambio cultural, con influencia de preceptos religiosos evangélicos y de moral occidental. Después de más de cincuenta años de contacto, una institución del orden social tradicional, la guerra, mantiene vigencia y se expresa como un espacio de reafirmación cultural en un contexto moderno, con un nuevo marco simbólico y referentes históricos y tradicionales previos al contacto. La guerra, para los waorani, es un articulador social que otorga prestigio a sus participantes y rememora el ethos tradicional waorani siendo una expresión vigente de la cultura tradicional.
\end{abstract}

Palabras clave: etnografía, guerra, pueblos amazónicos, interculturalidad, tradición cultural.

1 Este artículo expone los resultados de un trabajo etnográfico que consolidó un estudio de pericia antropológica, en el marco de un proceso judicial sobre la muerte de varios individuos de grupos familiares en aislamiento que habitan la Amazonía ecuatoriana.

2 Licenciado en Antropología por la Pontificia Universidad Católica del Ecuador. Perito antropólogo acreditado por el Consejo de la Judicatura de Ecuador. Investigador independiente en derechos humanos, antropología jurídica y pueblos amazónicos. Miembro de Society for the Anthropology of Lowland South America. Quito, Ecuador. Contacto: robertonarvaezc@gmail.com. 


\title{
Ethnography: a research instrument in legal an- thropology. A case of amazon people
}

\begin{abstract}
Legal anthropology refers its research and interpretation field to legal systems establishing the internal order of societies, and - in ethnography it has a research method with a systematic approach to cultural practices and particularities of social groups, analyzing and describing them for understanding its cultural aspects. Legal anthropology uses ethnography as a method for understanding the social order and legal systems prevailing in a human group. The case study refers us to the Waorani people who live in the Ecuadorian Amazon, contacted in the 1960s and in process of cultural change, influenced by evangelical religious precepts and Western morality. After more than fifty years of contact, an institution of the traditional social order, i.e. war, remains valid and expressed as a cultural reaffirmation in a modern context, with a new symbolic framework and historical and traditional references prior to contact. For the Waorani, war is a social articulator giving prestige to its participants and recalling the traditional Waorani ethos, being a current expression of the traditional culture.
\end{abstract}

Keywords: Ethnography, war, Amazonian peoples, interculturality, cultural tradition.

\section{A etnografia: instrumento de pesquisa em antropologia jurídica. $\mathrm{O}$ caso de um povo amazônico}

\begin{abstract}
Resumo
A antropologia jurídica remete seu âmbito de pesquisa e interpretação aos sistemas jurídicos que estabelecem a ordem interna das sociedades, e tem na etnografia um método de pesquisa que permite uma aproximação sistemática às práticas e particularidades culturais dos grupos sociais, analisando-os e desenvolvendo uma descrição que nos permite una compreensão de seus aspectos culturais. A antropologia jurídica utiliza a etnografia como um método que lhe permite uma compreensão da ordem social e dos sistemas legais imperantes em um grupo humano. O estudo de caso nos remete ao povo waorani que habita a Amazônia equatoriana, contatado na década do sessenta do século anterior e em processo de mudança cultural, com influência de preceitos religiosos evangélicos e de moral ocidental. Depois de mais de cinquenta anos de contato uma instituição da ordem social tradicional, a guerra, mantém vigência e se expressa como um espaço de reafirmação cultural em um contexto moderno, com um novo marco simbólico e referentes históricos e tradicionais prévios ao contato. A guerra, para os waorani, é um articulador social que outorga prestígio a seus participantes y rememora o ethos tradicional waorani sendo uma expressão vigente da cultura tradicional.
\end{abstract}

Palavras-chave: Etnografia, guerra, povos amazônicos, interculturalidade, tradição cultural. 


\section{Introducción}

La investigación antropológica requiere no solo de un sustento conceptual y metodológico que la enmarque, y de la rigurosidad científica que le permita interpretar toda la información recopilada y analizada de manera sistemática, sino de una serie de situaciones favorables que aportarán -y en muchos casos determinarán- la implementación o no de los instrumentos de investigación diseñados para el efecto, que nos permitirán acceder a información de carácter social y cultural, para comprender hechos y situaciones que se manifiestan en diferentes sociedades y las formas de pensamiento de las cuales se desprenden los mismos. Ya en la década de los 70 el antropólogo Geertz (1994 y 1996) señalaba que el ejercicio de la antropología tiene como esencia la interpretación y búsqueda de explicaciones a las expresiones sociales que, a los ojos occidentales, son ajenas, y de esa manera encontrar sus significaciones. Esas significaciones, de las que nos habla Geertz, deben lograrse a partir de una profundización en la investigación, un análisis cultural que llegue a un nivel de comprensión de los aspectos profundos de una sociedad, y que vayan más allá de una descripción de aquello que podría exponernos solo "apariencias" (Geertz, 1994, p. 56). Así, el antropólogo debe desarrollar la capacidad para acercarse a esa realidad de la forma más natural posible, en un ejercicio de beber de la fuente (Rueda, 1993), siguiendo la premisa de Claude Lévi-Strauss (1997, 2009 y 1964) de que la realidad verdadera no es nunca la manifiesta; por ello, acercarme a las fuentes de información fue una acción necesaria y prioritaria en la investigación de sociedades amazónicas. Justamente, la etnografía permite un análisis e interpretación de la información apegada al pensamiento y forma de ver el mundo de los actores de esa realidad, sus códigos y expresiones, su cotidianidad, sus relaciones y demás elementos. En el marco de la antropología jurídica, que requiere de una interpretación de realidades jurídicas diversas que coexisten (Díaz-Polanco, 2006) en los Estados modernos y sobre las cuales se requiere abordar las distintas visiones de mundo, la etnografía, en la práctica pericial 
antropológica, debe tener la capacidad de plantear argumentaciones y razones de convencimiento sobre conocimientos, hechos o prácticas culturales involucrados en casos judicializados (Matos, 2010; Valladares, 2011; Masapanta, 2009; García, 2007), suministrando al juez los elementos para el entendimiento de un caso específico o aportando indicios para demostrar hipótesis (Valladares, 2012) que tienen la posibilidad de convertirse en pruebas plenas cuando son consideradas en las sentencias emitidas por los jueces.

Desde 1998 participo como investigador en varios proyectos relacionados con procesos de planificación territorial desde una construcción participativa ${ }^{3}$, con un sustento fundamentalmente cultural y ambiental, integrando los aportes desde varias ciencias. En este proceso de investigación aplicada recorrí la mayoría de poblados waorani ${ }^{4}$ acompañado de jóvenes dirigentes, quienes hacían un esfuerzo por comprender el mundo occidental desde su cultura. En esa interrelación inequitativa, la sociedad nacional y nosotros como individuos no hemos sido los mejores referentes, ya que la información que ha sido transmitida hacia las nacionalidades y pueblos originarios ha sido aquella que se desarrolla en la periferia, y que viene cargada de prejuicios, exclusión, marginación, con todos los vicios y elementos negativos de la sociedad mayoritaria que han influido en crear y construir las formas de relacionamiento entre los pueblos originarios y los diferentes componentes del Estado (Rivas Toledo y Lara, 2001) 5 .

\footnotetext{
3 Se utilizaron técnicas etnográficas como entrevistas en profundidad, observación participante, talleres de investigación, grupos focales, desarrollados tanto con enfoques concretos de datos específicos, como del conocimiento ancestral sobre flora y fauna local, dinámicas de movilidad relacionada al uso de recursos y la concepción acerca de la guerra. En torno a este último aspecto, las entrevistas se remitieron al significado de la guerra, la relación con el territorio y las dinámicas de movilidad. El trabajo etnográfico contó siempre con guías e intérpretes, quienes aportaron mucho en la construcción interpretativa de la información.

4 Los waorani son una de las 15 nacionalidades indígenas que habitan en Ecuador. 5 Al respecto, Rivas y Lara exponen con mucha profundidad la forma de relacionamiento de los waorani con el Estado nación y sus actores, misma que es discutida en el presente artículo.
} 
Más aún cuando esos pueblos son de reciente contacto y cuyo proceso ha surgido de una presión desde actores puntuales, forzando las relaciones de comunicación y trato desde una visión colonialista, estableciendo dinámicas leídas como asistencialistas en las estructuras de relacionamiento (Rivas y Lara, 2001). En este marco, con fines de investigación pericial antropológica (Narváez, 2016), debí indagar con técnicas etnográficas acerca de un ataque realizado por waorani contra pueblos en aislamiento, para comprender las motivaciones que existieron, tratando de reconstruir las acciones realizadas en la correría de guerra, en un espacio marcado por la persistencia de la cultura tradicional waorani y la influencia cultural de actores externos. Esta información permitiría a los operadores de justicia una comprensión sobre las particularidades culturales de un grupo de reciente contacto (los waorani) en un marco de legislación nacional, en esencia monocultural (Walsh, 2012), en el que el asesinato se encuentra penado. La etnografía, en este caso, expuso los elementos culturales (Kalinsky, 2002) y prácticas particulares en una conducta punible (Regis Prado, 2011), con el fin de lograr su comprensión, en este caso, en un espacio judicial en el que la resolución o sentencia analiza el hecho delictivo (Amadeo, 2007) y las motivaciones culturales que se encuentran detrás.

\section{Los waorani y la persistencia de su cultura tradicional}

Para los waorani, los casi sesenta años de un contacto violento e inequitativo (Rivas Toledo, 2003) no han incidido en la ruptura total de su cultura, ni han consolidado su asimilación a las condiciones impuestas por el Estado nación; más bien, exponen la resistencia de la cultura waorani y la limitada capacidad del Estado y sus actores por alcanzar una comprensión de la diversidad y de las diferencias culturales (Trujillo Montalvo, 2016). Los mecanismos de relación del Estado (Trujillo Montalvo, 2018) con los pueblos de reciente contacto han ejercido cierta influen- 
cia en las actuales formas socio-organizativas y de conformación de asentamientos y poblados en el territorio de los waorani, sin eliminar la dinámica matrilocal por la cual los derechos territoriales vienen del lado de los antepasados de línea femenina y hacia donde se movilizan los waorani en determinados periodos de tiempo, en un ejercicio de traslado cíclico.

De esta manera, la praxis waorani identifica a los actores con los cuales es importante mantener una relación para dinamizar la forma de vida actual de cacería, pesca y recolección, sean petroleros, colonos, misioneros, operadores de turismo formal e informal, a los cuales se demanda su aporte con productos o servicios para beneficio familiar más que comunitario, ya que esa noción (comunitaria) no cabe en sociedades clánicas ${ }^{6}$, y más bien este comportamiento responde a la primacía de un orden autárquico, que mantiene una forma de subsistencia basada en la recolección de recursos. Dicha recolección ya no es de recursos de la selva, sino de recursos de aquellos actores que se desenvuelven en su territorio. Así, a diferencia del argumento establecido por Rivas y Lara (2001), que asignaban una alta incidencia de los actores en la forma de relacionamiento con los waorani, a la cual denominaron "relación asistencialista", nuestro análisis identifica una forma de relacionamiento establecida desde los waorani con los actores externos, en la cual se identifican prácticas o acciones de recolección", en las que los waorani conciben el territorio como territorio de abundancia de recursos ${ }^{7}$. Nuestro planteamiento considera que la forma de recolección es la particular, porque los actores externos son vistos como parte de la selva proveedora y,

\footnotetext{
6 La limitada comprensión del Estado sobre la diversidad ha hecho que se asuma que todos los pueblos originarios tienen carácter comunitario, siendo esto inaplicable en las sociedades de foresta tropical donde parte fundamental del orden social es la autarquía (Clastres, 1981); es decir, un constructo que permite un manejo del territorio como un espacio cultural en estado natural (Rivas, 2003), con control de grupos familiares o clánicos.

7 El territorio es visto como territorio de abundancia, en el cual pueden existir épocas marcadas por guerras o conflictos, que son las que establecen tiempos de escasez.
} 
por tanto, son objeto de recolección, de esta manera la forma de relación es establecida desde los waorani, imponiendo sus necesidades a los diferentes actores, y estos respondiendo a la misma con la entrega de lo solicitado, en la mayoría de los casos.

En las zonas de operación petrolera, es cotidiano encontrar maderos cruzados en las carreteras que se dirigen a los pozos petroleros, principalmente en la denominada Vía Auca, que conduce desde el Coca hasta el poblado de Tihuino, y por los ramales que se internan al interior del territorio waorani tradicional y a zonas colindantes con el Parque Nacional Yasuní, como una manera de "recolectar" dinero, alimentos, gaseosas y otros productos externos (Diario de campo, 2000).

Hay un contexto que abona a esta forma de relación, y es la dependencia de los actores externos, principalmente la industria petrolera, de garantizar el acceso al territorio waorani para realizar la explotación de estos recursos, y, por tanto, entregar o negociar sobre lo demandado se convierte en una necesidad. En la actualidad, gran parte del territorio ocupado por los waorani constituye un ambiente de territorio desbrozado, donde ellos mantienen la autoridad por los derechos heredados de los mayores y surgen recurrentes nominaciones a "país waorani", término formulado por varios dirigentes waorani que expresan su concepción de dueños del territorio y por tanto administradores plenos del mismo. Como pueblo de reciente contacto, los waorani mantienen muchos elementos culturales tradicionales, como las dinámicas de movilidad, la forma de relacionamiento intergrupal, la autarquía y la misma recolección; por su parte, el Estado ha tenido una escasa capacidad para poder plantear una relación equitativa (Trujillo Montalvo, 2001), y en su escasa presencia en la amazonía, sigue reproduciendo las dinámicas de cualquiera de los otros actores en el territorio, esto es, la negociación de los recursos, pero que se quedan en ofrecimientos por la limitada capacidad de gestión de las entidades públicas, salvo pocos casos 
en los que las entidades públicas tienen una mayor capacidad de inversión de recursos.

\section{Guerra y paz, continuum en un pueblo de reciente contacto}

\section{Ataque y venganza}

En marzo de 2013, un grupo de guerreros de varios poblados waorani ingresaron a la selva buscando ejecutar acciones de venganza por el ataque y muerte que sufriera una pareja de ancianos en el poblado de Yarentaro (Narváez, 2016): Ompore Omehuai y su esposa Buganei Caiga ${ }^{8}$. La pareja fue muerta por lanzas atribuidas a familias en aislamiento (Narváez, 2013a), en las cuales se reconoció una serie de rasgos decorativos y características físicas como contextura, confección y decoración que concuerdan con eventos de violencia anteriores y en los que los actores fueron pueblos en aislamiento. Las lanzas encontradas en los cuerpos de Ompore y Buganey (Narváez, 2013c) tenían mucha similitud con las que intervinieron en la muerte de Sandra Zavala y sus hijos Byron y Damaris Duche, en 2009 (Narváez, 2010), en el sector de la precooperativa Unión 2000 en la zona nor occidental limítrofe entre el Parque Nacional Yasuní y varios poblados colonos?.

\footnotetext{
8 De acuerdo con varios investigadores del proceso de contacto waorani (Boster, Yost y Peeke, 2003), ejerció un importante cambio en la cultura, principalmente en las acciones guerreras; sin embargo, después de 60 años de contacto, se han dado múltiples eventos de muerte que rememoran ese pasado y esas tradiciones que no se han perdido aún después de dos generaciones posteriores al contacto y que no vivieron de la forma tradicional waorani.

9 En 2010 fui designado perito especialista en culturas amazónicas para el desarrollo de un peritaje de las lanzas que intervinieron en la muerte de la familia Duche e identificación de la filiación cultural de las mismas. En el mismo año se me solicitó un estudio de las lanzas que provocaron la muerte del maderero Mariano Castellanos. Para los estudios antes indicados, hice una revisión total de las lanzas que intervinieron en ambos ataques, realizando un análisis tanto de la confección como de la decoración, encontrando varias particularidades en la tecnología y logrando compararlas con otras lanzas, como las que ocasionaron la muerte de Monseñor Alejandro Labaka, en 1988, y Carlos Omene, en 1993. Además,
} 
Otros eventos en los que existieron lanzas similares fueron los lanceamientos a Monseñor Alejandro Labaka, en 1988, a dos ancianos kichwa en una playa del río Curaray, en 2001, y a Mariano Castellanos, en 2007.

Posterior a la muerte de los ancianos, sus familiares cercanos organizaron las acciones de venganza, cuya iniciativa estuvo dirigida por los hijos mayores de Ompore; estos, siguiendo sus códigos y orden social, exigieron a sus familiares asumir su obligación como miembros de la unidad familiar o "nanicabo"10, y jugar un rol activo en la correría de venganza. En una reconstrucción del grupo familiar de Ompore y Buganei, se identificaron las relaciones de parentesco y, alrededor de ellas, el ejercicio de las alianzas ${ }^{11}$. Como se mencionó, el grupo inicial que organizó la venganza fue el de los hijos de Ompore, tanto los que correspondían a su primera mujer, Buganei, como de su segundo matrimonio, Ana Cawo. Entre los waorani se ha identificado la poliginia -un hombre con capacidad de casarse con más de una mujer-y la poliandria -una mujer tiene varios esposos-, que se evidencia en las relaciones sociales establecidas en el ataque. Así, los hijos de Ompore y Buganei que dirigieron la venganza fueron Cawime, Tewane y Boyotai, y Boya.

durante 2001 pude hacer una revisión pormenorizada de varias lanzas que fueron recuperadas de un ataque de pueblos en aislamiento contra dos ancianos kichwa en una playa del río Curaray, aguas abajo del poblado San José del Curaray, mientras estas permanecieron guardadas en una oficina de la organización waorani de esos años (Organización de la Nacionalidad Huaorani del Ecuador, ONHAE).

10 Es el grupo familiar formado por varias unidades domésticas o núcleos familiares emparentados entre sí.

11 Lévi-Strauus (1991) afirma que las alianzas mediante el matrimonio constituyen un hecho cultural, las cuales son una expresión del paso, generado por la prohibición del incesto, de la consanguinidad como hecho natural hacia una acción marcada por la cultura. Así, a través del matrimonio fuera del grupo familiar se garantiza la exogamia, la sobrevivencia física del grupo y se limita el riesgo de su desaparición. 
La etnografía: instrumento de investigación en antropología jurídica. El caso de un pueblo amazónico -

Ilustración 1. Grupo nuclear principal que organizó el ataque

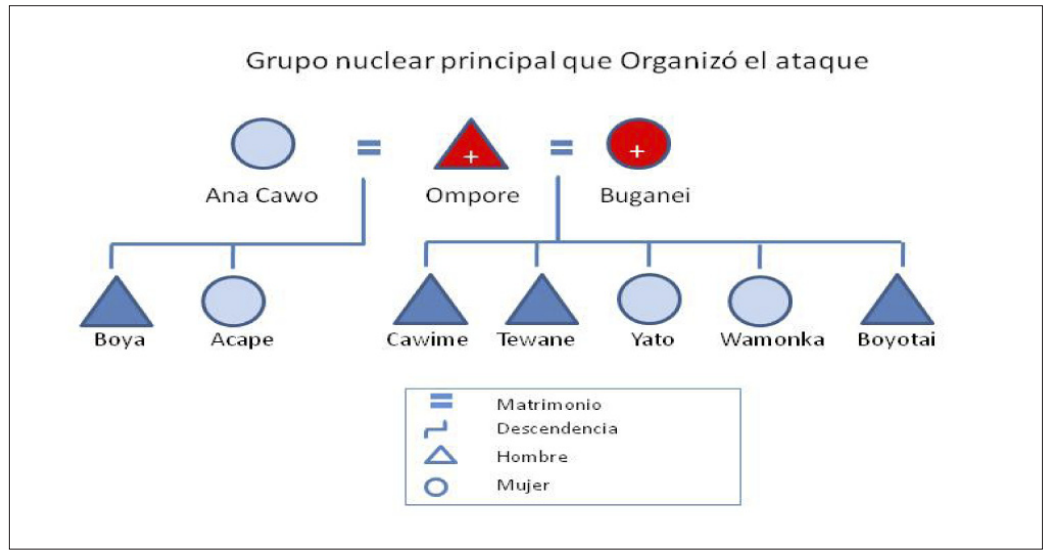

Fuente: elaboración propia.

En una obligación directa para participar en la venganza se encontraban los hermanos y parientes masculinos coetáreos de Ompore; esto es, su hermano (Araba) y el hermano de Buganei (Tagae). En este grupo también se encontraba el padre no biológico de Ompore, Inihua, casado también con su madre, Mimanca, que evidencia una alianza basada en la poliandria.

\section{Ilustración 2. Grupo familiar ampliado}

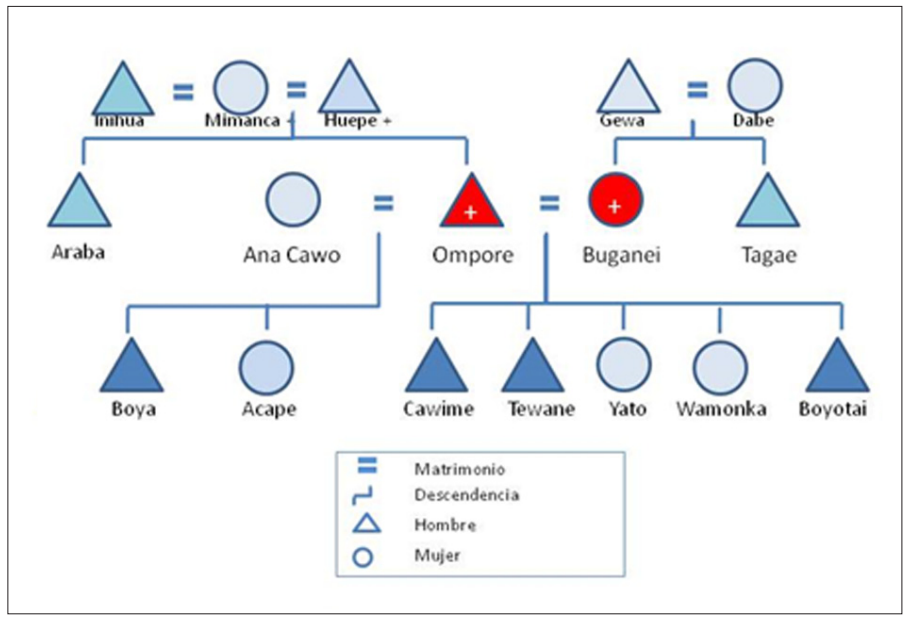

Fuente: elaboración propia. 
Con obligación marcada por las alianzas matrimoniales estaban los yernos de Ompore, a quienes sus hijos exigieron una participación activa, al existir acuerdos tácitos por el intercambio matrimonial (Entrevista en profundidad, 2014). De esta manera, Venancio, Yeti, Cowe y Kemo, se integraron a la correría de venganza. Según varios informantes, los hijos de Ompore amenazaron a sus cuñados, indicando que si no participaban de la venganza ellos serían los próximos muertos. En este punto se integra un nuevo elemento, que es la matrilocalidad, práctica por la cual el lugar de habitación es determinado por la mujer, de manera que los hombres viven en el territorio de la mujer, rodeados de sus familiares y, por tanto, en desventaja para su propia defensa; así, la mejor manera para la supervivencia es integrándose plenamente al grupo familiar de la esposa.

Ilustración 3. Grupo familiar ampliado y alianzas

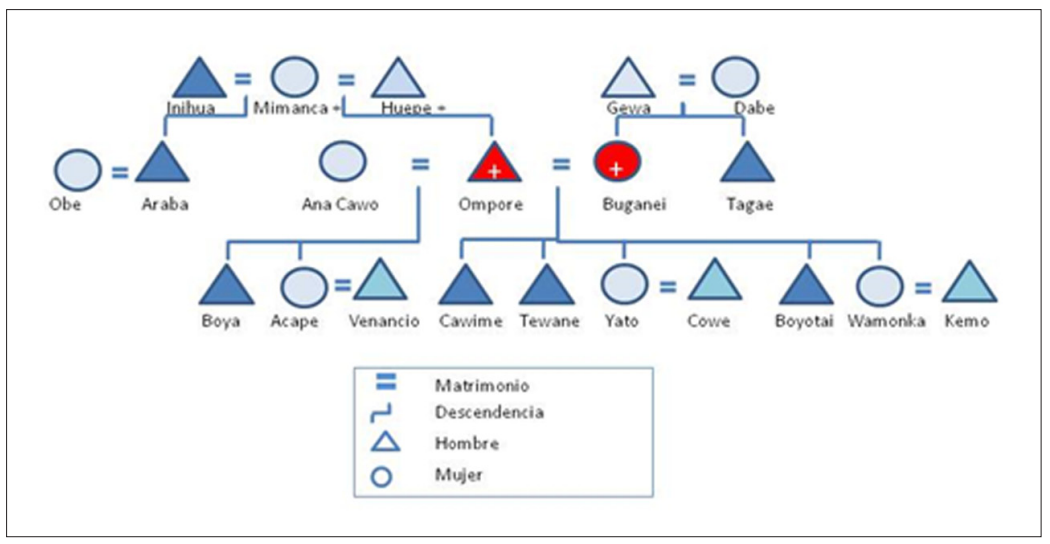

Fuente: elaboración propia.

A este grupo se unieron otros waorani, de los poblados donde habitaban los hermanos Cawime y Tewane, siempre con algún lazo de parentesco de sangre o simbólico, en búsqueda de reafirmar esas alianzas preexistentes o como una oportunidad para acumular prestigio; en este caso, a través de una acción tradicional sobre la cual en las últimas tres décadas no había existido un espacio para su ejecución. Como se distingue en el siguiente 
gráfico, los 17 individuos de color azul mantienen relaciones de parentesco, y fueron ellos quienes ejecutaron la correría de guerra contra un grupo familiar en aislamiento. En el cuadro se identifica solamente dos individuos sin relaciones de parentesco; sin embargo, su participación tuvo como motivación la oportunidad de poner en práctica una acción tradicional waorani enmarcada en su ethos y, en el caso de Cahuia, poder realizar una acción donde cobraría una venganza personal por un hecho ocurrido varios años ${ }^{12}$.

Ilustración 4. Atacantes

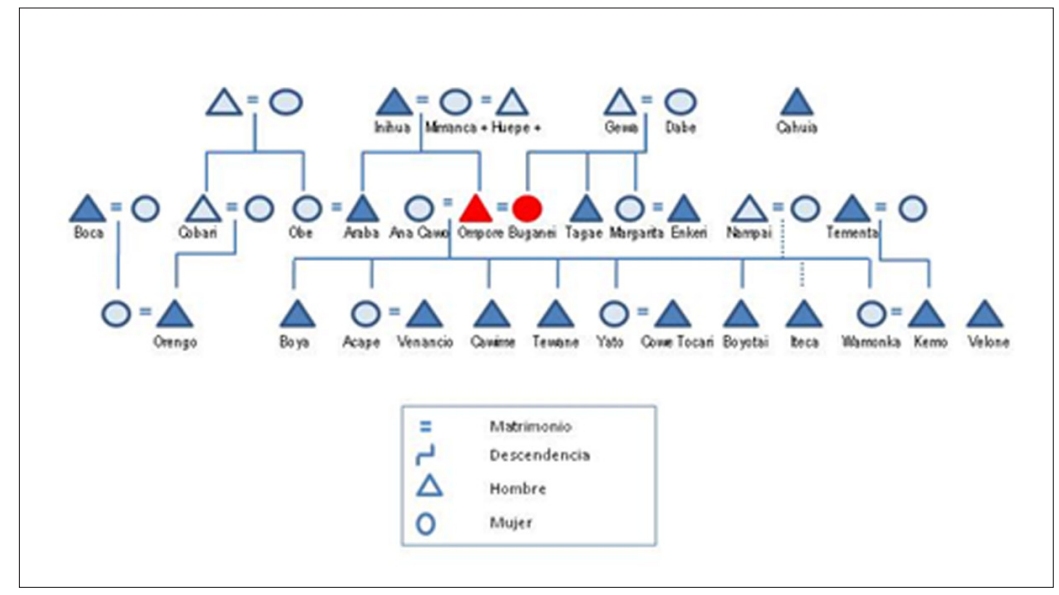

Fuente: elaboración propia.

De esta manera, se identifica que entre los waorani la venganza es una reacción social enmarcada en su cultura tradicional, en la que las alianzas se establecen a partir de relaciones de intercambio activas que son, para las sociedades, un contrato social (Mauss, 2010). En este caso, la muerte genera un espacio para activar las alianzas, poniendo en evidencia social los compromisos

12 En el transcurso de la investigación pude enterarme de que Cahuia habría sido víctima de un ataque de grupos familiares waorani que permanecieron en aislamiento, por lo cual tenía una deuda pendiente y una oportunidad para poder ejecutar una venganza personal. 
entre grupos familiares y, por tanto, los familiares de los muertos reciben el apoyo manifiesto para cualquier incursión de venganza. En algunos casos, los familiares de los fallecidos pueden exigir el cumplimiento de esos compromisos. De esta manera, dar es una obligación de los grupos familiares cercanos para reafirmar las alianzas existentes; de su parte, los familiares reciben esas manifestaciones de compromiso, que serán retribuidas en un futuro en caso de que los aliados así lo requieran.

\section{Guerreros contemporáneos y guerreros del pasado. Los líderes}

En el sentido de la investigación etnográfica, el acercamiento a los actores sociales es un punto clave: lograr un espacio adecuado para que la información logre fluir, pero no solo con un afán de investigación, sino sobre todo de poder compartir y comprender las dinámicas profundas de las culturas. El acceso a la información es igual de importante que la posterior interpretación de esta en el marco de un análisis teórico explicativo.

Así, entablar conversación con los ancianos waorani o con los líderes de los poblados requiere un acercamiento a través de un interlocutor que tenga algún nivel de familiaridad, y que abra el camino para un flujo de información directo, dinámico y sobre todo confiable con él o los informantes.

apenas ingresé al onko ${ }^{13}$, en compañía de mi intérprete, busqué un comportamiento lo más cercano a las prácticas de los waorani cuando arriban a una casa; así, hasta que el anfitrión nos invite a sentar permanecí de pie, tratando de no mostrarme ajeno al lugar, observando todo lo que había en su interior. Si bien la casa ya no corres-

13 Es la denominación en wao terero, idioma de los waorani, de las viviendas tradicionales waorani, que consisten en construcciones triangulares con estructura de madera y cobertura de hojas de palma entretejidas y atadas con fibras naturales. 
pondía a una casa típica, el concepto de orden interno se mantenía con los fogones como centro del espacio doméstico de cada unidad familiar residente, alrededor del cual se encuentran los ñ $o^{14}$ y otros elementos de uso cotidiano. Una cocineta a gas, donde se centraliza la preparación de los alimentos, un equipo de sonido, la televisión con conexión satelital, la radio de comunicaciones son elementos que contrastan con los fogones, hamacas, lanzas y omenas ${ }^{15}$. Una vez que el anfitrión se sentó en un banco junto al fogón de su unidad doméstica, me acerqué a ese sector de la casa y ocupé la hamaca, el fogón es el espacio donde se concentran las dinámicas de cada núcleo familiar.

Esta posición me permitía estar frente al dueño de casa y ser partícipe de la conversación. Allí, mientras se secaba algo de carne de monte sobre una canasta ubicada encima de la lumbre, me acomodé para escuchar la conversación que mantenía mi intérprete con el anciano. Todo se desarrolló en wao terero, con la gestualidad que utilizan los waorani para poner énfasis en la conversación, y que después de tantos años cerca de ellos uno puede interpretar, al menos en parte, el tema del que trata la charla (Diario de campo, 2013-2014).

El líder local mantiene una prevalencia sobre las familias del poblado, y es que entre los waorani el liderazgo es ocupado no solo por quien tiene mayor edad, sino por quien ha demostrado sus habilidades en la guerra, en la cacería o en la recolección, guiando y tomando las decisiones del nanicabo. El líder es quien garantiza la subsistencia del grupo, como proveedor de recur-

\footnotetext{
14 Es el término en wao terero utilizado para nominar a las hamacas, las cuales son confeccionadas con fibras de chambira (Astrocaryum chambira) en una forma de tejido particular, en la que los hilos se encuentran entrecruzados en paralelo, en una forma muy particular y diferente totalmente de las hamacas de otras nacionalidades y pueblos de la amazonía de Ecuador.

${ }_{15}$ Es el nombre en wao terero de las bodoqueras, utilizadas como arma para la cacería de aves y primates.
} 
sos en un entorno marcado por la abundancia, en donde la selva es un espacio doméstico de recolección (Rival, 2001). Se da un traslado permanente, ya sea de manera estacional o cíclica, en un continuum entre épocas de paz y de guerra (Narváez, 2018). Para los waorani, el líder tradicional tiene el reconocimiento por la historia de vida acumulada que viene de antes del contacto ${ }^{16}$, en la que existe un recuerdo latente de las guerras, de los guerreros, de los muertos; así, varios de los líderes de los poblados locales tienen el reconocimiento por haber defendido el territorio con lanzas, matando a "cohuri"17 o a waorani.

\section{Los roles dentro del orden social}

En la cultura waorani el rol que desempeña cada individuo es determinado por la acción y la práctica, pero sobre todo por los resultados, que se manifiestan en la capacidad de reproducción del grupo; estos resultados son productos de la selva, animales de cacería y el resultado de esa recolección constante de la sociedad waorani. Los roles expresan la relación con el entorno, ya sea de recolector o de cazador, y buscan la subsistencia; en tiempos de guerra será asegurar la supervivencia del "nanicabo". Los grupos familiares waorani son básicamente recolectores, la relación con la selva es la de un espacio que provee de los recursos necesarios para la subsistencia ${ }^{18}$, por tanto concretar esa relación sobre el espacio es lo que genera las dinámicas sociales (Rival, 2015) en tiempos de paz y en tiempos de guerra (Narváez, 2018).

\footnotetext{
16 Si bien varios grupos familiares fueron contactados en la década del 60 del siglo anterior, y otros permanecieron sin contacto hasta finales del 70, se mantienen aún varios grupos familiares que permanecen en aislamiento en distintas zonas de la región del Yasuní.

17 Para los waorani cohuri eran todos aquellos no waorani, a quienes se temía por considerárseles una amenaza para el territorio y el nanicabo, por ello era necesario combatirlos y matarlos, para evitar que regresaran más a amenazar su territorio.

18 La dieta waorani se basa en el uso de los productos de la selva, principalmente de la recolección, la cual se complementa con la cacería.
} 
En época de paz la selva, como espacio doméstico, abre la posibilidad de una serie de relaciones; se establecen alianzas, principalmente matrimoniales, se mantiene una movilidad tradicional relacionada con la ciclicidad, cacería y recolección de productos de la selva. Además, permite la posibilidad de mantener "kewenkode"19 o chacras de productos de periodo corto, como yuca, maní y otros. Por su parte, las épocas de guerra son una manifestación de ruptura de alianzas previamente existentes o imposibilidad de establecer alianzas potenciales. La movilidad es estratégica, esto es, traslados rápidos por el territorio hacia zonas de los antepasados, con la finalidad de alejarse de los enemigos, o el repliegue hacia el territorio de los antepasados en caso de ejecutar un ataque. Al existir mayor dinamismo, la subsistencia es básicamente de recolección y cacería, teniendo periodos en los que no tienen posibilidad de manejar kewenkode. De esta manera, la época de paz se expresa como una época de abundancia, de relaciones activas y dinámicas, mientras que la de guerra es una época de escasez, en la que la movilidad es más acentuada y se imitan las relaciones incluso con los grupos familiares afines.

Ilustración 5. Épocas de paz y de guerra
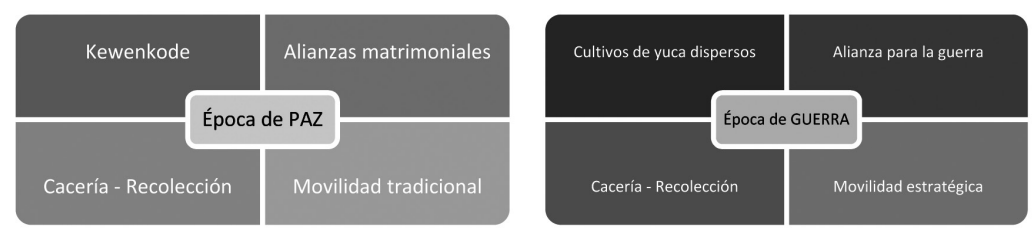

Elaboración propia a partir de: Rival (1996), Trujillo (2011), Cipolleti (2002), Cabodevilla (1999) y Tirdmarsh (1945).

\footnotetext{
19 Es un espacio en el que se cultivan productos de ciclo corto. Tradicionalmente, los waorani manejaban kewenkode, pero su dieta se basaba principalmente de productos de la recolección, que se relacionaba con los periodos de guerra y paz, donde las dinámicas de movilidad variaban.
} 
Mientras permanecía en la hamaca, reconstruía los momentos previos, para fijar la información que de a poco se me iba presentando, y es que desde el ingreso a la casa, no esperaba que el desarrollo del trabajo de investigación cumpliera el objetivo deseado, la intención de esa primera jornada era abrir un espacio de confianza que permitiera, a continuación, acercarme a la información etnográfica; sin embargo, todo fue tomando un ritmo acelerado (Diario de campo, 2013-2014).

\section{El ataque}

La conversación entre mi intérprete y el líder fue tomando confianza, las mujeres empezaron a servir Tepá ${ }^{20}$ en recipientes de calabaza ${ }^{21}$; se la entregaron primero al dueño de casa, quien asintió se brinde al invitado. Mientras continuaba la conversación y ante la pregunta del líder, mi interprete emitió un "si, él si toma, es casi waorani", a lo que enseguida me fue entregado un pilche de bebida (Diario de campo, 2013-2014).

La "Tepá" constituye una fuente importante de alimento en los waorani, que aporta con la hidratación y alimentación de sustento, desde tempranas horas de la mañana hasta el anochecer. La preparación está a cargo de las mujeres, quienes inician el trabajo de elaboración acudiendo al "kewenkode", donde recolectan las yucas que ya están listas y las llevan en canastos de fibra natural hacia los "onkos". Una vez allí, la lavan, la pelan y la cocinan. En

\footnotetext{
20 "Tepá" es el nombre en wao terero de la bebida preparada con yuca cocinada y fermentada con saliva, y es preparada por las mujeres del onko; es conocida en otras culturas como chicha. Para varios pueblos amazónicos la chicha es la fuente principal de alimentación, por el compuesto de carbohidratos y enzimas proteicas. Para los waorani la Tepá es una bebida de tiempos de paz, en la que existe la posibilidad de manejo del kewenkode y de cultivos relacionados con una movilidad estacionaria o de recolección de ciertos frutos de la selva, como la chonta o la ungurahua. Es importante exponer que la Tepá se prepara también de chonta y de ungurahua.

${ }^{21}$ Los recipientes son conocidos también con el término kichwa "pilche".
} 
un punto son retiradas del fuego y colocadas en bateas o se mantienen en las ollas, donde las aplastan y van tomando puñados de la masa para humedecerla en la boca y volver a colocarla en el recipiente del que fue extraída. Era habitual el uso de grandes recipientes de cerámica, que de a poco han sido reemplazados por ollas de aluminio. La "Tepá" es importante en la cultura waorani y también marca las épocas de abundancia. Así, en épocas de chonta se bebe una "Tepá" especial, al igual que en tiempo de ungurahua o petomo, cuya consistencia es más líquida y de sabor exquisito. En época de guerra la situación es diferente, pues el "kewenkode" se limita a cultivos ubicados estratégicamente en un territorio de movilidad dinámico, evitando asentamientos permanentes para evitar la posibilidad de un ataque, por tanto el consumo de "Tepá" se reduce.

Bebí la Tepá, y mientras lo hacía ponía atención a los gestos y palabras del Líder de la casa, inmediatamente le sirvieron un plato de losa con la presa de un ave cazada, acompañada de algunas yucas, de igual manera entregaron a mi interprete un plato de similares características, y posteriormente el mío. El ave había sido cocinada junto a las yucas por lo que el plato tenía algo de caldo, me entregaron una cuchara y disfruté de la comida. Cuando terminamos, una pequeña olla con agua sirvió para que nos limpiaramos la grasa y restos de comida de nuestras manos. Agradecí la comida, y la conversación siguió su curso, la narración se volvió intensa, mi intérprete me indicó: "graba", tenía mi grabadora entre las manos, junto a mi libreta de campo. "¿Puedo hacerlo?", pregunté, dirigiendo mi mirada al Líder, con la inquietud de tener la autorización del dueño de casa. "Sí", fue la respuesta, "él quiere que grabes". Encendí el aparato y seguía con atención la conversación, la gestualización y términos conocidos me daban luces de su contenido: "taramonta", "onko", "pinte", " aroke", "tapa", "ore" eran términos clave que junto a la gestualización detallaban el ingreso de 
un grupo de 17 waorani al interior de la selva para vengar el ataque y muerte de Ompore y su esposa. La mímica de toparse el estómago con la mano, y mover la otra en sentido negativo junto a la boca y afirmar "mea go mea", significaba que durante cuatro días no habían comido nada, y que la debilidad del cuerpo la compensaban con agua que bebían de pequeños esteros que cruzaban mientras caminaban sin rumbo por la selva.

El informante expresó con sus gestos la satisfacción al encontrar un "taramonta", sendero utilizado por las familias en aislamiento, detalló la dificultad de caminar por pantanos, realizando giros constantes que eviten quedar atrapados en los ciénegos. Con movimientos, indicó el cansancio y luego de tranquilidad por encontrar un "onko", donde pudieron descansar al identificar que se encontraba abandonado. Al continuar por el sendero, el Líder se esforzaba por expresar el miedo que tenían de una emboscada. La narración continúo indicando que un día después lograron llegar a otro "onko", donde encontraron varias "tapa ${ }^{22 "}$. En una gesticulación, su mirada me obligó a voltear la vista hacia una de las paredes, donde permanecían atadas varias lanzas que, a manera de trofeo, se las llevó de la casa atacada, puntualizando que las "tapa" que encontraron en la casa, anterior a la del ataque, no tenía ninguna decoración.

En medio de la charla el Líder interrumpió su narración y dio algunas indicaciones, que estuvieron dirigidas hacia el exterior, las mujeres se movieron, y hubo un alboroto cuyo ruido se fue alejando de a poco. Continuó detallando lo agreste de la selva y la abundancia de "petomo" o palmas de ungurahua (moretales), asimismo, indicando

22 En wao terero, lanzas confeccionadas con la madera de una palma denominada chonta. 
que existían muchas huellas de "ore" y "amo", especies de sahino que habitan en territorios de inundación, y que se alimentan de los frutos de las palmas. Esto llevó a que el dueño de casa indicara que en uno de los onkos abandonados a los que llegaron encontraran cráneos de sahino colocados sobre maderos, como una forma de exhibir la abundancia de dicho recurso y la habilidad de los habitantes de la casa para cazarlos.

Mientras la conversación fluía varios guerreros empezaron a ingresar a la casa portando lanzas grandes y pesadas, decoradas con mucha delicadeza y protegidas en su punta con papel. Los guerreros ingresaron y se apostaron al interior de la vivienda, cada uno sostenía orgullosamente lanzas hurtadas del lugar del ataque, como trofeos de una acción de reconocimiento social, y es que, como se dijo anteriormente, la venganza es un hecho social, una obligación que debe ser cumplida por los parientes cercanos y una forma de expresar los compromisos y alianzas existentes con otros grupos familiares (Diario de campo, 2013-2014).

A pesar de los años de contacto de los waorani y de la relación mantenida con el Estado nación, la guerra como acto social no ha desaparecido ni ha sido extirpada dentro de las prácticas culturales, contrario a lo planteado por Boster, Yost y Peeke (2003), quienes afirman que los waorani encontraron en la paz impuesta por los misioneros evangélicos del Instituto Lingüístico de Verano. Ellos, de acuerdo con este planteamiento, habrían logrado su fin de pacificar a los grupos waorani al imponer la figura religiosa del pecado y de la trascendencia de las almas; sin embargo, la reiteración de hechos de guerra lleva a cuestionar el planteamiento antes expuesto, ya que en este periodo temporal desde la época del contacto (1960) al presente, la sociedad waorani ha visto un vacío en su reproducción cultural. Así, varios hechos de violencia, en los cuales los waorani han manifestado su ser 
guerrero, nos hace reflexionar que para ellos, para los waorani, no es extraño participar en un ataque o guerra, porque este hecho reafirma su ser waorani, reconecta al individuo con el ethos tribal en el que la pertenencia al grupo se manifiesta con acciones que conecten con el "Duranibai" (Ima Omene, 2012) o época pasada. La exhibición de las lanzas era justamente para lucir hacia el resto del grupo el resultado del valor utilizado en ingresar a la selva y todos los hechos de guerra de los cuales formaron parte: la ritualidad, en fin, la cultura; una exposición para consolidar el prestigio, su reconocimiento social, ejercer el ser waorani.

Mientras las mujeres servían Tepá a los visitantes, el Líder seguía explicando cómo encontraron un camino que los llevaría a la casa del grupo familiar en aislamiento que fue atacado, la narración exponía a detalle la organización de la incursión final, la división en dos grupos, uno para afrontar el ataque por la puerta principal del onko, y otro para reducir a quienes hagan el intento de escapar por la puerta posterior. Los atacantes reconocieron que portaban armas, aunque indicaron que ingresaron además con lanzas y que en el onko deshabitado que encontraron antes había una importante cantidad de "tapas" que las tomaron para realizar el ataque.

La narración reconocía varios muertos, y se afirmaba era un grupo grande, "tien" indicó con fuerza el anfitrión, poniendo énfasis con ambas manos que movían los dedos de manera repetitiva. Aunque se conoce que los onkos tradicionales pueden albergar entre 40 y 50 habitantes, es posible que el que fue atacado, y que estaba recién siendo construido, pudo tener aproximadamente 40 habitantes. Cien implicaba un grupo grande, en la noción waorani de cantidad, y por tanto la posibilidad de muchas muertes (Diario de campo, 2013-2014).

En la narración, la reafirmación de muerte o de haber matado otorga un estatus especial al waorani, un prestigio reconocido por 
el "nanicabo" y los nanicabos cercanos, ya que se exhibe su rol y papel como proveedor, en este caso de seguridad para el grupo, al haber eliminado la amenaza de un grupo enemigo con el cual no fue posible establecer alianza alguna; es de esta manera, a partir de la práctica de las tradiciones waorani, en que se construye el ethos, o "ideal" de lo que es ser waorani. De igual manera, la acción permite una conexión del presente con el pasado, de la continuidad cultural waorani, de las nociones culturales relacionadas con el "Duranibai", es decir, la vida pasada, en la que los waorani tradicionales eran quienes defendían su territorio tradicional y garantizaban la supervivencia del grupo familiar a través de la recolección y cacería, y cuando se requería la muerte de los adversarios que constituían una amenaza a la seguridad del grupo.

El detalle del ataque exponía el número de muertos de cada uno, gestualizando el uso de armas de fuego y la muerte de personas mientras intentaban huir (Narváez, 2013). En un momento se llegó a comparar el hecho con la cacería de huanganas, porque un ataque grupal puede aniquilar a muchos individuos, exponiendo así la relación con el entorno y la actividad de cacería como fuente de subsistencia.

Finalizada la narración, el anciano se puso de pie y se acercó a la pared de su casa donde tenía atadas las lanzas que recuperó del ataque. Las 3 lanzas constituían verdaderas obras de arte, por su diseño, decoración y estilización, obras de arte elaboradas en madera de chonta, decoradas con fibras vegetales, entre ellas chambira, plumas de distintas aves, de varios colores, y pelos de oso hormiguero gigante. Obras de arte confeccionadas para matar, para saldar venganzas, para defender al grupo, para ser waorani (Diario de campo, 2013-2014).

Es justamente en la parte final de la narración en la que se identifica la persistencia del ethos waorani, a pesar de haber pasado aproximadamente 60 años en un proceso intensivo de cambio cultural, en el cual muchos elementos materiales e inmateriales 
externos han llegado a formar parte de la vida cotidiana waorani, pero, a pesar de aquello, aún persiste el ethos, que consiste en todos aquellos rasgos particulares de una sociedad que la identifican y la cohesionan. Así, la guerra, la venganza por las muertes, es un elemento latente en la vida social waorani, que construye y reconstruye las formas sociales internas y las de relacionamiento con el exterior; esta vida, a pesar de no desarrollarse dentro de los parámetros culturales tradicionales, ha generado una adaptación, incorporando elementos externos y limitándose además de elementos tradicionales, ejerciendo una ritualidad que integra lo tradicional y lo moderno que reafirma la cultura waorani en un nuevo tiempo.

\section{Las lanzas}

Tradicionalmente los waorani mantenían un ritual para la elaboración de lanzas, que iniciaba con el establecimiento de un acuerdo de guerra, ya sea para defensa o para ataque, e integraba los individuos de sexo masculino en jornadas de corte de palmas de chonta, o lo que los waorani denominan "tumbar chontas", selección de segmentos de la palma con los que se confeccionará las lanzas. A continuación, se trasladan esos segmentos seleccionados de la chonta hacia el onko, donde los hombres darán la forma y los detalles (Narváez, 2013b). La habilidad de la sociedad waorani para la confección de las lanzas se manifiesta en que éstas llegan a tener el mismo largo e incluso peso, lo que evidencia una práctica continua en la elaboración de estos implementos y una gran habilidad ${ }^{23}$. La confección se realiza fuera del onko, en un espacio que permita la utilización de fuego para "hacer fuerte

23 El peritaje antropológico de las "lanzas que ocasionaron la muerte de la familia Duche" (Narváez, 2010a) identificó patrones recurrentes en lo que se refiere al largo y peso de las lanzas, así como en la decoración; además de diferencias entre lanzas, con lo que se concluyó que estas fueron confeccionadas por diferentes personas. De igual manera, se pudo identificar, a partir de las características antes indicadas, que los individuos que realizaron el ataque fueron varios y atacaron a más de una de las víctimas. 
a la lanza" ${ }^{24}$ e impedir que esta se tuerza. Los detalles de la lanza consisten en un mayor volumen en la punta, donde se pueda tallar dientes aserrados que impidan la extracción de la lanza una vez esta atraviese un cuerpo. El número de dientes depende de cada individuo, pero en general tienen al menos cinco filas. La punta tiene como característica tener una forma cónica romboidal en cuya base se tallan los dientes, mientras el lomo de la punta es redondeado como para permitir una mayor penetración en el cuerpo. El segmento medio de la lanza es tallado con un menor diámetro, de manera de permitir que una persona pueda portar varias lanzas en cada mano. Las lanzas se dejan secar y, para ello, se colocan contra los onkos o contra un cerco que se forma entre los árboles cercanos al "onko". Mientras las lanzas se secan los hombres van preparando las plumas que utilizarán para la decoración, las fibras y otros elementos que, tanto por su color como por su origen, determinarán las características de la lanza. La lanza lleva decoración en sus tres segmentos: cerca de la punta, en el lugar donde se empuña y se porta la lanza, y en el segmento final. Tanto en el sector de la punta como en el final la decoración utilizada es fibra de chambira, plumas y cerdas de animales. De esta manera, las lanzas resumen la complejidad del pensamiento de la sociedad waorani en torno a su visión del mundo y, sobre todo, respecto de la acción de la muerte.

Una entrevista que realicé años atrás al líder de un "nanicabo" waorani, Manuel Cahuia, líder del poblado waorani de Ñoneno, ubicado a orillas del río Shiripuno y vecino de grupos familiares en aislamiento, la decoración de las lanzas expresa la intención del fabricante y la carga emocional de este para la acción de matar.

Lanza con plumas negras de gallinazo son para que el cuerpo del muerto se pudra y sea comido por estos animales. Lanza con pelos de oso banderón son para de-

24 Entrevista a Tehuane Omehuay, junio de 2013. 
mostrar la fuerza y el coraje que tiene este animal para enfrentar a cualquier enemigo. Lanza con plumas rojas o pintadas con chonta son decoradas de esta manera para que la lanza se llene de sangre. Lanza con plumas de águila arpía demuestran la fuerza del guerrero para atacar (Entrevista a Manuel Cahuia, octubre de 2009, Río Shiripuno).

Las lanzas que decoraban ahora la casa del anciano y que fueron sustraídas por el grupo de guerreros waorani del nanicabo en aislamiento atacado, eran largas y pesadas, con un nivel de estilización tal que exponían la destreza para su confección. Detalles como un acanalamiento delicado en los costados de la lanza denotaban una habilidad ganada con la práctica en la elaboración de lanzas. En otras lanzas, de ataques de pueblos en aislamiento y que ocasionaron varias muertes como las de Mariano Castellanos en el 2006 (Narváez, 2010b), Sandra Zavala, Byron y Damaris Duche en el 2009 (Narváez, 2010a), Ompore Omehuay y Buganei Caiga en 2013 (Narváez, 2013c), pude encontrar los acanalamientos en mención, que pueden deberse a rasgos particulares desarrollados por un autor, que no necesariamente ha participado en los ataques antes indicados ${ }^{25}$.

Cada uno de los atacantes presentes me permitió apreciar cada una de las lanzas que trajo como trofeo, el nivel de estilización era tal que exponía una gran habilidad de los autores. Cada uno portaba con orgullo las lanzas, como un símbolo palpable de valor, de un valor que le otorgaba un prestigio de guerreros, por su valentía, por haber cumplido el acto social de venganza y haber cumplido

\footnotetext{
25 Un aspecto importante, recopilado en uno de los ingreso a territorio waorani, me permitió analizar en forma particular las lanzas que ocasionaron la muerte de Ompore y Buganei, y que se encontraban en posesión de uno de sus hijos, quien me presentó varias de las réplicas que había realizado de las lanzas, pero que no lograba conseguir similar peso, y detalles como el brillo volumen en la punta y los acanalamientos. El informante me indicó la diferencia en peso y volumen que pude corroborar y era evidente (Entrevista Tehuane Omehuay. Junio de 2013. Yarentaro).
} 
su obligación masculina y familiar que les permite reafirmar ser waorani, no por su ascendencia sino por ejercer su rol social waorani (Diario de campo, 2013-2014).

\section{¿Acto de iniciación?}

De vuelta a la hamaca, la narración se concentró en los detalles del ataque, el nivel de participación de cada uno de los miembros del grupo de guerreros y la estrategia que les permitió sobrevivir. La narración del líder señalaba la división en dos grupos, uno, el que arremetió contra los habitantes del onko, y que estaba conformado por los hijos y yernos, y que portó armas de fuego, donde se concentraban quienes tenían una obligación social y familiar de ejecutar la venganza. El segundo grupo conformado por quienes tenían menos responsabilidad social de venganza, los más jóvenes, inexpertos y el más viejo, quienes con un par de armas se encargarían de emboscar la huida por la parte posterior del onko y así proteger a los otros miembros del grupo ${ }^{26}$. En este segundo grupo participaron no tanto por obligación directa, pero si como una posibilidad de iniciación a ser waorani en el sentido de la tradición (Diario de campo, 2013-2014).

Tres fueron los ancianos que participaron del ataque, quienes en su momento participaron en guerras contra otros grupos waorani y contra "cohuri"; sin embargo, en esa época ellos eran jóvenes, posiblemente recién iniciados en este tipo de acciones. Casi 60 años después ellos fueron los que guiaron al grupo, haciendo conocer a los más jóvenes las estrategias de guerra tradicionales. Así, los familiares de Ompore y Buganei ejecutaron la venganza,

\footnotetext{
26 En una entrevista realizada a uno de los jóvenes que formo parte del segundo grupo, indicó que el más anciano les habría dicho "si quieren sobrevivir quédense conmigo", aduciendo su experiencia para asegurar la huida posterior al ataque (Entrevista a Paa Velone. Julio de 2013. Coca).
} 
incorporando armas de fuego y ejerciendo un poder mayor sobre el grupo atacado, con una ventaja tecnológica superior, que pudo haber ocasionado muchas más muertes que en un ataque tradicional.

Los detalles del ataque, por parte de los guerreros, señalaron la muerte de más de 50 personas que, contrastados posteriormente con entrevistas personales, develó que en varios casos se exageró la cantidad y que en otros no ocasionaron ni una muerte, pero que sí participaron en el rito de clavar lanzas en los muertos. También indicaron la huida de varios de los habitantes del "onko", principalmente niños y jovencitos, quienes se escurrieron por sus paredes, por lo que quienes tenían lista la emboscada tuvieron pocas oportunidades de actuar.

Un detalle importante fue la narración del inicio del ataque, en la cual el escenario se convirtió en un espacio mítico, donde el "onko", al sentir el ataque, se levantó en el aire y una tormenta arremetió el lugar con viento y lluvia, caída de rayos y truenos, convirtiéndose en una narración extraordinaria que es recurrente en las historias de guerra waorani, en las que eventos sobrenaturales se escurren entre hechos reales, como una manera de integrar lo mitológico con lo real.

Entre los apuntes que realicé en el diario de campo, una nota interrogativa señala: "acto de iniciación?" como un elemento a ser analizado, y es que de todos los participantes, pocos habían participado previamente en alguna guerra, o pocos tuvieron una edad antes del contacto -que en el grupo Huepeiri al que pertenecen fue finales de las década del 70-, en la cual las acciones de guerra eran una parte activa de las dinámicas sociales cotidianas. Por ello, y a pesar de que las narraciones de guerra y cantos que mantienen la cultura viva, el evento se constituyó en un espacio de iniciación, en un rito mediante el cual se pasó desde la carga simbólica componente de los cantos y narraciones a un hecho fáctico en el que la experiencia a través de la acción permitió el 
ejercicio del símbolo, y el paso de la narración al hecho, a la vivencia del símbolo, al símbolo en acción (Rueda, 1982).

En las sociedades humanas, la iniciación es un espacio de transición en el periodo de vida que permite el paso, en diferentes etapas concebidas por las diferentes sociedades, hasta un estadio en el cual se alcanza la plenitud del ejercicio de la cultura. En el caso de los waorani, el estadio es el que consolida al individuo como ser pleno, esto es, con las capacidades para ejercer sus roles y responsabilidades sociales; en el caso de los hombres, como un actor eficiente en la relación con el entorno natural, en la que su accionar garantiza la provisión para la seguridad del grupo familiar: proveedor de alimentos (a partir de la recolección y cacería) o proveedor de seguridad como guerrero.

\section{Conclusión}

La etnografía es una herramienta de investigación que permite recopilar información y contrastarla entre sí. El uso de distintas técnicas permite adentrarse en una cultura desde diferentes ámbitos y profundizar en información cualitativa que permite no solo una exposición de información, sino la interpretación de la misma, construyendo datos y permitiendo reconstruir las dinámicas sociales, articulando tanto los aspectos evidentes como aquellos que se ocultan detrás de discursos, diálogos y prácticas que, sin una comprensión del contexto, pueden llegar a no tener sentido.

Además de la aplicación de modelos teórico-metodológicos, el acercamiento a una realidad es fundamental. Lograr la interacción con los actores sociales es uno de los aspectos más importantes, porque permite tener una lectura integral de las dinámicas sociales, de sus actores y de la relación con el pasado y el presente de una sociedad que se articula no solamente de manera lineal, sino mediante formas que desarrollan su comprensión del mundo.

La investigación etnográfica fue una herramienta que permitió acceder a información para reconstruir un hecho social, que en 
el contexto de la justicia ordinaria evidencia conductas punibles, pero dentro de una interpretación plural exige una comprensión mayor de esas manifestaciones, relacionándolas con el contexto de una cultura determinada, y que requiere de espacios de análisis intercultural para que esa comprensión de las particularidades culturales pueda tener el abordaje legal correspondiente.

El ataque de los waorani debe ser visto como una práctica de reproducción de la guerra. Fue un escenario donde los waorani de varios poblados pudieron reafirmar la práctica de la cultura tradicional y tener un espacio de transición de waorani genérico a waorani étnico ${ }^{27}$, tras un proceso intensivo de aculturación desde un Estado envolvente, que en un accionar excluyente no ha podido comprender las dinámicas culturales de las nacionalidades y pueblos originarios, más aún de los pueblos de reciente contacto, e integrarlos con un reconocimiento de las particularidades y formas de vida tradicional, a un concepto de Estado inclusivo, que genere conciencia de las diferencias y de las normas que deben prevalecer, marcadas por el derecho a esas particularidades, pero también a una convivencia.

Adicionalmente, los ancianos que participaron pudieron hacer ejercicio de las prácticas tradicionales, en un contexto actual en el cual se incorporaron ciertas tecnologías, como las armas de fuego, constituyéndose en un escenario de reproducción de una cultura dinámica, cambiante, donde persisten ciertos elementos pero se actualizan otros, donde la esencia waorani se actualiza conforme al contexto en el que se desenvuelven desde el contacto.

\section{Epílogo}

"Y en ese escenario de reivindicación, de prestigio, de guerreros modernos con bagaje tradicional, y de un antropólogo embebido en las historias fue terminando la

27 En el sentido de cambio cultural planteado por Ribeiro (1971). 
tarde, las palabras no se acabaron, sino que continuaron, en un diálogo íntimo, entendible solo para los waorani, donde la reafirmación del hecho como acción de responsabilidad con la familia y en cumplimiento de la obligación de venganza era la tónica de un hecho social llevado a la práctica como evidencia tangible de ser waorani, como una expresión de que la cultura está viva, y que ha superado 60 años de un contacto forzado, donde el Estado en su accionar excluyente y racista no ha permeado, y donde las acciones waorani seguirán siendo waorani, como una afirmación de resistencia ante una cultura externa de la cual los waorani solo han tomado lo que han considerado útil o de su agrado, y donde seguirán reproduciendo su ethos waorani con cantos de guerra que sinteticen y que incluyan la guerra de la que formaron parte los nuevos guerreros, entre música de vallenatos y reguetón, alimentados con yuca, verde, carne de monte, y del codiciado pan con cola, arroz con pollo y otros productos facilitados desde la petrolera o las instituciones públicas, en una reproducción de una relación que puede ser vista como desigual, pero que, desde los waorani, es una práctica más de recolección, y que continúa estableciendo la noción de "grandes hombres" a esos personajes waorani con capacidad y habilidad para interactuar con los actores del Estado y canalizar elementos en beneficio propio y de su grupo familiar cercano, por no ser sociedades comunitarias sino clánicas.

Con la llegada de la tarde fue cayendo también el deseo de hablar y, antes de ser considerado una interferencia para dinámicas sociales propias, me levanté de la hamaca, tome en mis manos la grabadora y la apagué, agradecí al dueño de casa y su familia, recibí el último cuenco de tepá, me despedí de los guerreros y demás presentes y salí de la casa. Afuera el sol mantenía su brillo y su calor, y retorné como de un laberinto de tiempo al con- 
texto de la Amazonia del norte, esto es un poblado de casas de cemento, cancha cubierta, con pocos servicios básicos y una población en el borde de lo tradicional y la marginalidad. El conductor respiró aliviado al ver que regresábamos sin problema, consciente que aún existían ánimos acalorados y una cierta barrera que habíamos logrado superar, y que nos permitió tener acceso a mucha información, pero sobre todo que nos permitió ser recibidos en una condición de iguales, a diferencia de la actitud que mantenemos desde la sociedad nacional con los pueblos y nacionalidades originarias (Diario de campo, 2013-2014).

\section{Referencias}

Amadeo, S. (2007). La acción en la teoría del delito. Buenos Aires: Editorial Universidad.

Boster, J., Yost, J. y Peeke, C. (December de 2003). Rage, Revenge and Religion: Honest Signaling of Aggression and Nonaggression in Waorani Coalitional Violence. Ethos, 31(4), 471-494.

Cabodevilla, M. (1999). Los Huaorani en la historia de los pueblos del oriente. Coca: CICAME.

Cabodevilla, M. (2004). El exterminio de los pueblos ocultos. Coca: CICA$\mathrm{ME}$.

CDES. (30 de enero de 2012). Ompore: me dijeron los Taromenani. Recuperado de: https: / / www.youtube.com/watch?v=qcYpj9cOrI8

Cerón, C. y Montalvo, C. (1998). Etnobotánica de los Huaorani de Quehueri - Ono. Quito: Abya Yala.

Cipolleti, M. (2002). El testimonio de Joaquina Grefa, una cautiva quichua entre los waorani (Ecuador, 1945). Journal de la Societe des Americanistes (En Ligne).

Clastres, P. (1981). La cuestión del poder en las sociedades primitivas, en P. Clastres, Investigaciones en antropología Política (pp. 109-116). Barcelona.

Descola, P. (1996). La selva culta. Quito: Abya Yala.

Descola, P. (2001). Construyendo naturaleza, ecología simbólica y prác- 
tica social, en P. Descola \& G. Pálsson, Naturaleza y sociedad. Perspectivas antropológicas (pp. 101 - 123). México: Siglo XXI editores.

Díaz-Polanco, H. (2006). Elogio de la diversidad. Globalización, multiculturalismo y etnofagia. México: Siglo XXI.

García, D. (2007). Pluralismo jurídico y peritaje antropológico: su incidencia en la educación y legislación ecuatoriana. En II Congreso Ecuatoriano de Antropología y Arqueología. Balance de la última década: Aportes, retos y nuevos temas. Tomo II. Quito: Abya Yala, Banco Mundial.

Geertz, C. (1994). Conocimiento local: ensayos sobre la interpretación de las culturas. Barcelona: Paidós clásica.

Geertz, C. (1996). La interpretación de las culturas. Madrid: Gedisa.

Goldaraz, M. (2013). La Historia de los aislados y la indiferencia hacia sus vidas. Centro de Derechos Económicos y Sociales. Recuperado el 24 de diciembre de 2015, de: http:/ / www.observatorio. cdes.org.ec/113-noticias/ultimo-minuto/456-lectura-imprescindible-la-historia-de-los-aislados-y-la-indiferenciahacia-sus-vidas

Gómez García, P. (1981). La antropología estructural de Claude Lévi-Strauss. Madrid: Editorial Tecnos.

Ima Omene, M. (2012). Saberes waorani y Parque Nacional Yasuní: plantas, salud y bienestar en la Amazonía del Ecuador. Quito: Iniciativa Yasuní ITT, Ministerio Coordinador de Patrimonio, Ministerio del Ambiente, Programa de las Naciones Unidas para el Desarrollo (PNUD) y Fondo para el Medio Ambiente Mundial (FMAM).

Kalinsky, B. (2002). La pericia antropológica como herramienta de investigación social. AIBR, Antropólogos Iberoamericanos en Red, (25).

Labaka , A. (1988). Crónica huaorani. Coca: CICAME.

Lévi-Strauss, C. (1964). Mitológicas. Lo crudo y lo cocido. México: Fondo de Cultura Económica.

Levi-Strauss, C. (1991). Las estructuras elementales del parentesco. Barcelona: Paidós.

Lévi-Strauss, C. (1997). Tristes trópicos. Barcelona: Paidós.

Lévi-Strauss, C. (2009). Las estructuras elementales de parentesco. Barcelona: Paidós. 
Maldonado , P. (20 de Marzo de 2016). Mapa Región del Yasuní. Información base de la Región del Yasuní. Quito: Documento técnico sin publicar.

Masapanta, C. (2009). El derecho indígena en el contexto constitucional ecuatoriano. En Derechos ancestrales: justicia en contextos plurinacionales. Quito: Ministerio de Justicia y Derechos Humanos.

Matos, J. (2010). ¿La interculturalidad se abre paso en las Cortes Superiores de Justicia de la Amazonía peruana? Ponencia presentada en el VII Congreso Internacional dela Red Latinoamericana de Antropología Jurídica. Lima.

Mauss, M. (2010). Ensayo sobre el Don: forma y funciones del intercambio en las sociedades arcaicas. Madrid: KATZ Editores.

Narváez, R. (2010a). Peritaje cultural de las lanzas que intervinieron en la muerte de la familia Duche. Francisco de Orellana: Fiscalía 3 de la provincia de Orellana.

Narváez, R. (2010b). Peritaje cultural de las lanzar que intervinieron en la muerte de Mariano Castellanos. Francisco de Orellana: Fiscalía 1 de la provincia de Orellana.

Narváez, R. (2013). Experticia antropológica de elementos culturales para identificar formas de vida tradicionales y elementos externos que pudieran incidir en procesos de violencia en familias en aislamiento a partir del reconocimiento del lugar de los hechos. Quito: Fiscalía General del Estado. Comisión de la Verdad y Derechos Humanos.

Narváez, R. (2013a). Estudio de Antropología Jurídica sobre los hechos ocurridos en el Yasuní, en el poblado de Yarentaro. Informe técnico sin publicar, Fiscalía General del Estado. Quito: Comisión de la Verdad y Derechos Humanos.

Narváez, R. (2013b). Alcance al Estudio de Antropología Jurídica. Informe técnico sin publicar, Fiscalía General del Estado. Quito; Comisión de la Verdad y Derechos Humanos.

Narváez, R. (2013c). Análisis coparativo de lanzas Tagaeri Taromenane que han intervenido en muertes y ataques. Quito: Fiscalía General del Estado. Comisión de la Verdad y Derechos Humanos.

Narváez, R. (2014). Estudio socio-poblacional del Territorio Sapara. Quito: Terra Mater.

Narváez, R. (2016). ¿Un ejercicio de aplicación de la justicia intercultu- 
ral? El caso waorani en la Amazonía ecuatoriana. Antropologías del Sur, (6), 163-179.

Narváez, R. (2018). La incómoda presencia de grupos familiares de pueblos indígenas en aislamiento (PIA) en la región del Yasuní, Amazonía ecuatoriana. Tipití: Journal of the Society for the Anthropology of Lowland South America, en edición.

Narváez, R. (julio de 2016). Intercambio, guerra y venganza: el lanceamiento de Ompore Omehuai y su esposa Buganei Caiga. Antropología Cuadernos de investigación, (16), 99-110.

Oficina del Alto Comisionado de Naciones Unidas para Derechos Humanos. (2012). Directrices de protección para los pueblos indígenas en aislamiento y en contacto inicial de la Región Amazónica, el Gran Chaco y la región oriental de Paraguay. Ginebra: OACNUDH.

Patzelt, E. (2002). Los huaorani: Los últimos hijos libres del jaguar. Quito: Banco Central del Ecuador.

Regis Prado, L. (2011). La norma penal como norma de conducta. Revista de Derecho Penal y Criminología, 3(5), 145-172.

Ribeiro, D. (1971). Fronteras indígenas de la civilización. México: Siglo XXI Editores.

Rival, L. (1996). Hijos del sol padres del Jaguar. Quito: Abya Yala.

Rival, L. (2001). Cerbatanas y lanzas, la significación social de las elecciones tecnológicas de los huaorai. En P. Descola y G. Palsson, Naturaleza y sociedad. México: Siglo XXI Editores.

Rival, L. (2013). Informe de peritaje de lanzas de Yarentaro. Coca: Fiscalía de Orellana.

Rival, L. (2015). Transformaciones huaoranis: frontera, cultura y tensión. Quito: Universidad Andina Simón Bolívar, Abya-Yala, Latin American Centre-University of Oxford.

Rivas, A. (2003). Sistema mundial y pueblos indígenas en la Amazonía: a propósito del ataque a los tagaeri (Coyuntura). Íconos: Revista de Ciencias Sociales. FLACSO Ecuador, 17, 21 - 30.

Rivas, A. (2006). Los pueblos indígenas en aislamiento desde los derechos humanos y la conservación de la biodiversidad. Curitiba, Brasil: Texto para la Octava Conferencia de las Partes, Convenio de Diversidad Biológica.

Rivas Toledo, A. y Lara, R. (2001). Conservación y petróleo en la Amazonía ecuatoriana. El caso waorani. Quito: Abya Yala - EcoCiencia. 
Rueda, M. (1982). Mitología. Quito: Pontificia Universidad Católica del Ecuador.

Rueda, M. (1993). Mitología. Quito: Pontificia Universidad Católica del Ecuador.

Tirdmarsh, W. (1945). Unarranged Notes on the Aucas of the Nushiño Basin. Mecanografiado.

Trujillo Montalvo, P. (2001). Salvajes, civilizados y civilizadores. La amazonía ecuatoriana el espacio de las ilusines. Quito: Abya Yala, Fundación de investigaciones andino amazónicas.

Trujillo Montalvo, P. (2016). Código guerrero: movilidad, guerra y muerte con lanzas. Antropología Cuadernos de Investigación, (16), 85-98.

Trujillo Montalvo, P. (2018). Identificación y dinámicas de los Pueblos Indígenas en Aislamiento Voluntario (PIAV) en el Yasuní. Boletín de Antropología, 33(55), 271-296.

Trujillo, P. (2011). Boto Waorani, Bito Cowuri. La fascinante historia de los Wao. Quito: Fundación FIAAM.

Valladares, L. (2011). El peritaje antropológico. Los retos del entendimiento intercultural. En G. Baeza Espejel y N. Ramón, Pueblos indígenas, Debates y perspectivas. México: Editorial Programa, Universidad Autónoma de México.

Valladares, L. (2012). La importancia del peritaje cultural: avances, retos y acciones del Colegio de Etnólogos y Antropólogos Sociales, A.C. (CEAS) para la certificación de peritos. En Peritaje antropológico en México: reflexiones teórico metodológicas y experiencias. México: Boletín Colegio de Etnólogos y Antropólogos Sociales.

Walsh, C. (2012). Interculturalidad, crítica y pluralismo jurídico: Reflexiones en torno a Brasil y Ecuador. En C. Walsh, Interculturalidad y (de) colonialidad. Ensayos desde el Abya Yala. Quito: Abya Yala, Instituto de Culturas Indígenas ARY.

Yost, J. (1978). El desarrollo Comunitario y la Supervivencia Étnica. El caso de los huaorani, Amazonía Ecuatoriana. Quito: Instituto Lingüístico de Verano - Ministerio de Educación y Cultura del Ecuador. 